\title{
Core temperatures during major abdominal surgery in patients warmed with new circulating-water garment, forced-air warming, or carbon-fiber resistive-heating system
}

\author{
Kenji Hasegawa $\cdot$ Chiharu Negishi $\cdot$ \\ Fumitoshi Nakagawa $\cdot$ Makoto Ozaki
}

Received: 14 May 2010/Accepted: 1 December 2011/Published online: 22 December 2011

(C) The Author(s) 2011. This article is published with open access at Springerlink.com

\begin{abstract}
Purpose It has been reported that recently developed circulating-water garments transfer more heat than a forced-air warming system. The authors evaluated the hypothesis that circulating-water leg wraps combined with a water mattress better maintain intraoperative core temperature $\geq 36^{\circ} \mathrm{C}$ than either forced-air warming or carbonfiber resistive heating during major abdominal surgery.

Methods Thirty-six patients undergoing open abdominal surgery were randomly assigned to warming with: (1) circulating-water leg wraps combined with a full-length circulating-water mattress set at $42^{\circ} \mathrm{C}$, (2) a lower-body forced-air cover set on high $\left(\approx 43^{\circ} \mathrm{C}\right)$, and $(3)$ a carbonfiber resistive-heating cover set at $42^{\circ} \mathrm{C}$. Patients were anesthetized with general anesthesia combined with continuous epidural analgesia. The primary outcome was intraoperative tympanic-membrane temperature $\geq 36^{\circ} \mathrm{C}$.

Results In the $2 \mathrm{~h}$ after anesthesia induction, core temperature decreased $1.0 \pm 0.5^{\circ} \mathrm{C}$ in the forced-air group, $0.9 \pm 0.2^{\circ} \mathrm{C}$ in the carbon-fiber group, and $0.4 \pm 0.4^{\circ} \mathrm{C}$ in the circulating-water leg wraps and mattress group $(P<0.05$ vs. forced-air and carbon-fiber heating). At the end of surgery, core temperature was $0.2 \pm 0.7^{\circ} \mathrm{C}$ above preoperative values in the circulating-water group but remained $0.6 \pm 0.9^{\circ} \mathrm{C}$ less in the forced-air and $0.6 \pm 0.4^{\circ} \mathrm{C}$ less in the carbon-fiber groups $(P<0.05$ vs. carbon fiber).
\end{abstract}

K. Hasegawa · C. Negishi · F. Nakagawa · M. Ozaki $(\bowtie)$ Department of Anesthesiology, Tokyo Women's Medical University, 8-1 Kawada-cho, Shinjuku, Tokyo 162-8666, Japan e-mail: mozaki@anes.twmu.ac.jp

C. Negishi

Saiseikai Kawaguchi General Hospital, Kawaguchi, Japan
Conclusions The combination of circulating-water leg wraps and a mattress better maintain intraoperative core temperature than did forced-air and carbon-fiber warming systems.

Keywords Temperature - Hypothermia .

Circulating-water garment $\cdot$ Carbon fiber $\cdot$ Forced air

\section{Introduction}

Perioperative hypothermia causes numerous postoperative complications, including morbid cardiac events [1-3], wound infection $[4,5]$, and coagulopathy [6, 7]. Postoperative hypothermia influences muscle strength and delays recovery from muscle relaxants $[8,9]$. Even mild hypothermia prolongs postanesthetic recovery [10]. Consequently, the standard of care is now to maintain intraoperative core temperature $\geq 36^{\circ} \mathrm{C}$ unless hypothermia is specifically indicated [11].

All general anesthetics produce dose-dependent impairment of thermoregulatory control $[12,13]$. Neuraxial anesthesia also impairs central and peripheral control of thermoregulation [14]. The combination of general and epidural anesthesia produces both central and peripheral impairment, with the result that the combination is worse than either alone [15]. Maintaining normothermia is challenging during major open abdominal surgery because heat is lost from the abdominal cavity by evaporation [16] (although the amount has yet to be quantified in humans).

Various types of perioperative patient-warming devices have been developed since the 1980s. Numerous studies demonstrate that convective (forced-air) heating is among the most effective methods of preventing intraoperative core hypothermia [17]. Forced-air warming is remarkably 
safe, is comfortable even in nonanesthetized patients, and is easy to use. It has thus become by far the most commonly used perioperative warming approach. The efficacy of carbon-fiber resistive heating is comparable with forcedair warming [18]. However, forced-air warming or resistive heating may be insufficient to maintain perioperative normothermia during some procedures, such as major abdominal surgery under general and epidural anesthesia, surgery for polytrauma, liver transplantation, and off-pump coronary artery bypass grafting [19, 20]. It is thus worth considering alternative approaches.

Circulating-water mattresses transfer relatively small amounts of heat and by themselves are rarely sufficient to maintain normothermia. However, several types of circulating-water garments have become available. These devices are more effective [21], as they involve more of the skin surface and, especially, anterior portions of the body where most heat loss occurs [22]. Most circulating-water systems include posterior heating or can be combined with circulating-water mattresses. We therefore compared the efficacy of the combination of a circulating-water garment and mattress to the forced-air warming and carbon-fiber resistive-heating systems during major abdominal surgery under general anesthesia combined with epidural analgesia.

\section{Methods}

With approval of the Ethics Committee at Tokyo Women's Medical University and patients' informed consent, we studied 40 patients undergoing elective major abdominal surgery. All were American Society of Anesthesiology (ASA) physical status 1 or 2 and aged from 20 to 80 years old. Patients with preoperative fever, evidence of current infection, thyroid disease, or dysautonomia were excluded from the study. Patients were premedicated with $2-3 \mathrm{mg}$ midazolam and $0.5 \mathrm{mg}$ atropine $30 \mathrm{~min}$ before induction of anesthesia. An epidural catheter was inserted via an interspace between T8 and L1 using standard techniques; $3 \mathrm{ml}$ of $2 \%$ lidocaine with epinephrine was given as a test dose. Subsequently, 6-10 ml $0.5 \%$ bupivacaine with $2.5 \mu \mathrm{g} / \mathrm{ml}$ fentanyl was injected. Additional bupivacaine/fentanyl solution was injected to obtain at least a T4-L1 sensory block. Epidural anesthesia was maintained during surgery with a continuous infusion of $0.125 \%$ bupivacaine with fentanyl $(2.5 \mu \mathrm{g} / \mathrm{ml})$ solution at a rate of $5-10 \mathrm{ml} / \mathrm{h} ; 5 \mathrm{ml}$ $0.25 \%$ epidural bupivacaine was given during surgery if deemed necessary by the attending anesthesiologist. General anesthesia was induced using $1.5-2 \mathrm{mg} / \mathrm{kg}$ propofol and maintained with a propofol infusion combined with $60 \%$ nitrous oxide to keep the bispectral index (BIS) at 40-60. Patients were paralyzed with vecuronium and mechanically ventilated. All fluids administered were warmed to $35-37^{\circ} \mathrm{C}$, and ambient temperature was kept near $22^{\circ} \mathrm{C}$.

Randomization was based on computer-generated codes that were maintained in sequentially numbered opaque envelopes. The participants were randomly assigned to warming with: (1) a pair of circulating-water leg wraps (Rapr-Round Body Wraps, Gaymar Industries, New York, $\mathrm{NY}$, USA) and a full-length circulating-water mattress (Gaymar) set to $42^{\circ} \mathrm{C}$ (circulating-water group), (2) carbonfiber resistive-heating blankets (SmartCare, Geratherm Medical AG, Germany) set to $42^{\circ} \mathrm{C}$ (carbon-fiber group), or (3) a lower-body, forced-air cover with the controller set to high (Bair Hugger ${ }^{\mathrm{TM}}$, Arizant Healthcare, Inc., MN, USA) (forced-air group). The of leg-wrap garments were connected to each other and then connected to the water circulator outlet (MediTherm II, Gaymar), and the other circulator outlet was connected to the water mattress. Only a thin cotton sheet was permitted between the circulatingwater mattress and the patient. The carbon-fiber blanket covered the left arm, chest, and both legs. The forced-air and resistive-heating warmers covered roughly 15-20\% of the skin surface, whereas the combined circulating-water wraps and mattress covered roughly $30 \%$ of the skin surface [23]. All warmers were started at induction of general anesthesia and maintained throughout surgery. Patient demographic and morphometric characteristics were recorded; vital signs were recorded every $15 \mathrm{~min}$; duration of surgery, fluid balance, and total-required propofol dose were recorded. Mean skin temperature was calculated from temperatures recorded at four cutaneous sites using the following formula: mean skin temperature $=0.3\left(T_{\text {chest }}+\right.$ $\left.T_{\text {arm }}\right)+0.2\left(T_{\text {thigh }}+T_{\text {calf }}\right)$ [24]. Core temperature was measured at the right tympanic membrane using aural probes. The probes were inserted by the patients or by the investigators until the patient felt the thermocouple touch on the tympanic membrane; appropriate placement was confirmed when the patient easily detected a gentle rubbing of the attached wire. The aural canal was then occluded with cotton and the probe taped in place. Mean body temperature was calculated from a formula: $\mathrm{MBT}=$ $0.64 T_{\text {core }}+0.36 T_{\text {skin }}$ [25]. Ambient temperature was measured with a thermocouple positioned at the level of the patient but well away from any heat-producing equipment. Measurements started before anesthesia induction and continued throughout surgery at 15-min intervals. All temperatures were measured with Mon-a-therm thermocouples (Covidien, Boulder, CO, USA).

A sample size of 12 patients in each group was sufficient to detect a clinically important difference of $1.0^{\circ} \mathrm{C}$ in core temperature among groups, assuming a standard deviation (SD) of $0.7^{\circ} \mathrm{C}$, using a general linear model (GLM) repeated measures, a power of $80 \%$, and a significance level of $5 \%$. Calculations are based on our previous temperature 
Table 1 Demographic, morphometric, and perioperative factors
Only initial and final core temperatures were compared statistically. Results are presented as mean \pm atandard deviation

$\mathrm{SpO}_{2}$ oxygen saturation, $\mathrm{PCO}_{2}$ partial pressure of carbon dioxide

* $P=0.01$ versus circulatingwater group

\begin{tabular}{|c|c|c|c|}
\hline & Circulating water & Carbon fiber & Forced air \\
\hline Number of patients & 12 & 12 & 12 \\
\hline Age (years) & $59 \pm 10$ & $64 \pm 10$ & $63 \pm 13$ \\
\hline Sex (male/female) & $8 / 4$ & $6 / 6$ & $7 / 5$ \\
\hline Weight $(\mathrm{kg})$ & $60 \pm 9$ & $58 \pm 7$ & $56 \pm 10$ \\
\hline Body mass index $(\mathrm{kg} / \mathrm{m})$ & $23 \pm 4$ & $23 \pm 2$ & $22 \pm 2$ \\
\hline Surgical duration (min) & $241 \pm 68$ & $250 \pm 56$ & $241 \pm 82$ \\
\hline Mean skin temperature $\left({ }^{\circ} \mathrm{C}\right)$ & $34.4 \pm 1.0$ & $34.2 \pm 0.8$ & $34.3 \pm 0.7$ \\
\hline Mean body temperature $\left({ }^{\circ} \mathrm{C}\right)$ & $35.7 \pm 0.6$ & $35.3 \pm 0.5$ & $35.4 \pm 0.5$ \\
\hline Heart rate (beats/min) & $67 \pm 11$ & $68 \pm 11$ & $75 \pm 11$ \\
\hline Mean arterial pressure $(\mathrm{mmHg})$ & $79 \pm 11$ & $82 \pm 9$ & $81 \pm 8$ \\
\hline $\mathrm{SpO}_{2}(\%)$ & $99.2 \pm 1.1$ & $99.8 \pm 0.2$ & $99.7 \pm 0.7$ \\
\hline End-tidal $\mathrm{PCO}_{2}(\mathrm{mmHg})$ & $34 \pm 2$ & $31 \pm 3$ & $33 \pm 1$ \\
\hline Administered fluid $(\mathrm{ml} / \mathrm{kg} / \mathrm{h})$ & $12 \pm 4$ & $15 \pm 4$ & $16 \pm 6$ \\
\hline Urine output $(\mathrm{ml} / \mathrm{kg} / \mathrm{h})$ & $2 \pm 1$ & $4 \pm 2$ & $4 \pm 5$ \\
\hline Blood loss (ml/kg) & $6 \pm 5$ & $10 \pm 9$ & $10 \pm 14$ \\
\hline Propofol (mg/kg/h) & $6 \pm 2$ & $6 \pm 2$ & $6 \pm 2$ \\
\hline Ambient temperature $\left({ }^{\circ} \mathrm{C}\right)$ & $22.0 \pm 0.5$ & $22.5 \pm 0.6$ & $22.1 \pm 0.5$ \\
\hline Initial core temperature $\left({ }^{\circ} \mathrm{C}\right)$ & $36.7 \pm 0.3$ & $36.6 \pm 0.4$ & $36.8 \pm 0.3$ \\
\hline Core temperature at end of surgery $\left({ }^{\circ} \mathrm{C}\right)$ & $36.9 \pm 0.7$ & $36.0 \pm 0.6^{*}$ & $36.2 \pm 0.9$ \\
\hline
\end{tabular}

studies. Core temperatures are presented as a function of intraoperative time, with anesthesia induction considered elapsed time zero. All other intraoperative measurements were averaged over time in each patient and then averaged among patients given each treatment. GLM repeatedmeasures test was used to determine possible statistically significant differences in core temperature changes from time 0 to $120 \mathrm{~min}$, and at the end of the surgery among treatment groups. Data were analyzed using the SAS (ver. 9.3) program for windows. Core temperature changes throughout the study within each group and other data such as vital signs were compared by one-factorial analysis of variance (ANOVA). Results are presented as mean $\pm \mathrm{SD}$, and $P<0.05$ was considered statistically significant.

\section{Results}

Four patients were excluded by the criteria, 12 were assigned to each group, and each patient completed the study. Surgery duration averaged $244 \pm 68 \mathrm{~min}$ and was comparable in all groups. Surgery types were also comparable among groups and included gastrectomy, cholecystectomy, hepatectomy, and hemicolectomy. Patient demographic and morphometric characteristics were similar in each group. Surgical factors; initial core, ambient, mean skin, and mean body temperatures; fluid balance; propofol requirements; and vital signs during surgery were also similar. The tympanic membrane temperature averaged $36.7 \pm 0.3^{\circ} \mathrm{C}$ at anesthesia induction and did not significantly differ among groups (Table 1).

Core temperatures significantly dropped just after anesthesia induction in all groups $(P<0.05$, from $15 \mathrm{~min}$ to at least $90 \mathrm{~min}$ after anesthesia induction) and decreased $\approx 0.9^{\circ} \mathrm{C}$ in the hour after anesthesia induction. Subsequently, it increased in the circulating-water group but remained essentially unchanged in patients assigned to forced-air or carbon-fiber warming. A multivariate analysis of variance $(3 \times 10 \mathrm{GLM}$, with three group levels and ten time levels) repeated-measures test was performed on core temperature data, and there was a significant group-by-time interaction, $F(2 / 297)=4.43, \quad P<0.05$. The post hoc comparison using Sheffe's $F$ test showed core temperatures $2 \mathrm{~h}$ after anesthesia induction and at the end of surgery were significantly greater in the circulating-water group than with the other two approaches $[F(2 / 33)=3.28$, $P<0.05$ vs. forced-air and resistive-heating groups at $120 \mathrm{~min}$ after anesthesia induction, $F(2 / 33)=3.28$, $P<0.05$ vs. resistive-heating group at the end of surgery] (Fig. 1).

Compared with temperatures at anesthesia induction, core temperature at the end of surgery was $0.6 \pm 0.9^{\circ} \mathrm{C}$ less in the forced-air group and $0.6 \pm 0.4{ }^{\circ} \mathrm{C}$ less in the resistive-heating group; in contrast, the decrease was only $0.2 \pm 0.7^{\circ} \mathrm{C}$ in the circulating-water group (Table 2), and as a result, core temperature of the circulating-water group was $36.9 \pm 0.7^{\circ} \mathrm{C}$. No complications related to any of the warming methods were observed. 


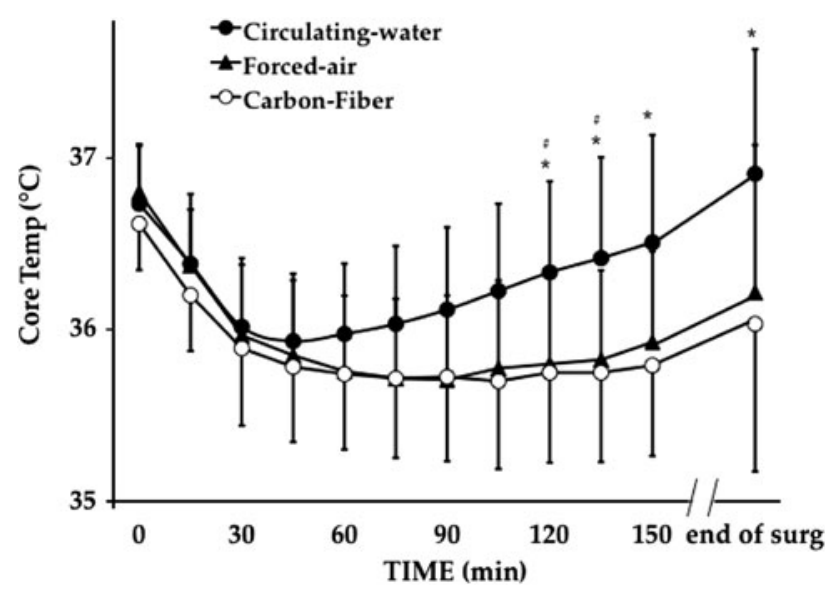

Fig. 1 Core temperature as a function of time in patients assigned to the circulating-water, forced-air, and carbon-fiber warming groups. All groups comprised 12 patients, except for at $150 \mathrm{~min}$, when the forcedair group had 11. Temperature changes in the circulating-water group differed significantly from the other groups after $120 \mathrm{~min}$. Temperatures in forced-air and resistive-heating groups never differed significantly. Results are presented as mean \pm standard deviation (SD). \#Significant difference versus forced-air group, *significant difference versus carbon-fiber group; $P=0.05$. Core temperature at the end of surgery was $36.9 \pm 0.7^{\circ} \mathrm{C}$ (circulating-water group), $36.2 \pm 0.9^{\circ} \mathrm{C}$ (forced-air group), and $36.0 \pm 0.6^{\circ} \mathrm{C}$ (carbon-fiber group)

Table 2 Core temperatures

\begin{tabular}{llll}
\hline & $1 \mathrm{~h}$ & $2 \mathrm{~h}$ & $\begin{array}{l}\text { End of } \\
\text { surgery }\end{array}$ \\
\hline Circulating-water group & $-0.8 \pm 0.3$ & $-0.4 \pm 0.4$ & $0.2 \pm 0.7$ \\
Carbon-fiber group & $-0.9 \pm 0.3$ & $-0.9 \pm 0.2^{*}$ & $-0.6 \pm 0.4^{*}$ \\
Forced-air group & $-1.0 \pm 0.4$ & $-1.0 \pm 0.5^{*}$ & $-0.6 \pm 0.9$ \\
\hline
\end{tabular}

Elapsed times are referenced to anesthesia induction. Temperatures were measured with a tympanic-membrane thermocouple. Results are presented as mean \pm standard deviation $\left(\% \geq 36^{\circ} \mathrm{C}\right)$

* Significant differences versus circulating-water group $(P=0.05)$

\section{Discussion}

Our patients were at special risk of hypothermia because they had major open abdominal surgery under combined general and epidural analgesia. Average final intraoperative core temperatures nonetheless averaged at least $36^{\circ} \mathrm{C}$ in all groups. However, in $50 \%$ of those warmed with a forcedair system and in $58 \%$ of those randomized to a resistiveheating system, core temperature stayed $<36^{\circ} \mathrm{C}$ at the end of surgery; in contrast, in $83 \%$ of circulating-water-system patients, core temperature returned $36^{\circ} \mathrm{C}$. The combination of circulating-water leg wraps and a circulating-water mattress better maintained intraoperative core temperature than forced-air warming or resistive-heating systems.

Taguchi et al. [21] evaluated a whole-body circulatingwater garment and found that it warmed better than forced air. Our results extend theirs because it compared three systems rather than two and because it was conducted in surgical patients rather than volunteers. Others have also shown that circulating-water garments outperform forcedair systems [26-29]. However, even during major open abdominal surgery under combined epidural/general anesthesia, forced-air systems kept most patients' core temperature $\geq 36^{\circ} \mathrm{C}$. Numerous studies show that forced-air warming maintains core temperature $\geq 36^{\circ} \mathrm{C}$ during less challenging circumstances. Because forced-air warming is inexpensive and remarkably safe, it remains the most obvious warming method for routine cases.

Thermal sensation varies considerably as a function of body region. For example, the upper chest and face are far more sensitive to temperature changes than the rest of the skin surface [30]. Remarkably, humans can detect increases in forehead temperature of only $0.001{ }^{\circ} \mathrm{C} / \mathrm{s}$ [31]. However, unlike thermal sensation, actual heat transfer across various anterior surface regions probably does not differ enormously. In contrast, posterior heat transfer is compromised in the supine position because the weight of the patient compresses cutaneous capillaries. Reduced perfusion has two important consequences: The first is that dependent skin has less ability to dissipate absorbed heat to the rest of the body, thus reducing the efficacy of posterior heat transfer [17, 22]. The second is that heat accumulation, combined with pressure, can provoke pressure-heat necrosis (burns) [32, 33]. Thermal injury has also been reported with circulating-water garments [34].

Posterior heating does transfer some heat, although considerably less than anterior heating. In contrast, forcedair warming by design does not warm dependent surfaces; this feature somewhat reduces efficacy but markedly improves safety. Previous work suggests that forced-air warming and circulating-water garments transfer comparable amounts of heat on the anterior surface, with circulating-water garments being more effective simply because it includes posterior warming [21]. The most likely explanation for our results is that heat transfer was comparable with forced-air warming, resistive-heating systems, and leg wraps-and that the slightly improved efficacy in the circulating-water group resulted from a small amount of heat transferred through the posterior surface by the circulating-water mattress.

Many types of forced-air systems are available, and the efficacy of each is comparable [35]. In contrast, the efficacy (and safety) of various resistive-heating systems is likely to differ considerably, as heat transfer with electrically-heated covers is critically dependant on how well the cover contacts the skin surface which, in turn, is highly influenced by design details. Our results with the SmartCare system therefore should not be extrapolated to other resistive-warming systems: instead, each needs to be 
specifically evaluated. The same is surely true for various posterior circulating-water systems.

A limitation of our study is that we did not directly quantify cutaneous heat transfer with each system. However, mean body temperature can reliably be estimated from core and mean skin temperatures [26]. Although there were no significant differences among mean body temperatures for each group, the circulating-water group showed higher tendency of mean body temperature (Table 1), thus it could be indirect proof of better heat transfer.

In summary, circulating-water leg wraps combined with a circulating-water mattress maintained core temperature better than resistive-heating or forced-air skin warming during major abdominal surgery under general and epidural analgesia. Improved efficacy with the circulating-water approach probably results from inclusion of the circulatingwater mattress, which increased total available warmed surface area. Circulating-water mattresses can cause burns and should be used with considerable caution. For most patients, forced-air-which is inexpensive and has an admirable safety record-probably remains the best approach.

Open Access This article is distributed under the terms of the Creative Commons Attribution Noncommercial License which permits any noncommercial use, distribution, and reproduction in any medium, provided the original author(s) and source are credited.

\section{References}

1. Frank SM, Beattie C, Christopherson R, Norris EJ, Perler BA, Williams GM, Gottlieb SO. Unintentional hypothermia is associated with postoperative myocardial ischemia. The Perioperative Ischemia Randomized Anesthesia Trial Study Group. Anesthesiology. 1993;78:468-76.

2. Frank SM, Fleisher LA, Breslow MJ, Higgins MS, Olson KF, Kelly S, Beattie C. Perioperative maintenance of normothermia reduces the incidence of morbid cardiac events. A randomized clinical trial. JAMA. 1997;277:1127-34.

3. Insler SR, O'Connor MS, Leventhal MJ, Nelson DR, Starr NJ. Association between postoperative hypothermia and adverse outcome after coronary artery bypass surgery. Ann Thorac Surg. 2000;70:175-81.

4. Kurz A, Sessler DI, Lenhardt R. Perioperative normothermia to reduce the incidence of surgical-wound infection and shorten hospitalization. Study of Wound Infection and Temperature Group. N Engl J Med. 1996;334:1209-15.

5. Sheffield CW, Sessler DI, Hunt TK. Mild hypothermia during isoflurane anesthesia decreases resistance to $E$. coli dermal infection in guinea pigs. Acta Anaesthesiol Scand. 1994;38: $201-5$.

6. Akca O, Sessler DI. Thermal management and blood loss during hip arthroplasty. Minerva Anestesiol. 2002;68:182-5.

7. Hofer CK, Worn M, Tavakoli R, Sander L, Maloigne M, Klaghofer R, Zollinger A. Influence of body core temperature on blood loss and transfusion requirements during off-pump coronary artery bypass grafting: a comparison of 3 warming systems. J Thorac Cardiovasc Surg. 2005;129:838-43.

8. Heier T, Caldwell JE, Sessler DI, Miller RD. Mild intraoperative hypothermia increases duration of action and spontaneous recovery of vecuronium blockade during nitrous oxide-isoflurane anesthesia in humans. Anesthesiology. 1991;74:815-9.

9. Heier T, Caldwell JE. Impact of hypothermia on the response to neuromuscular blocking drugs. Anesthesiology. 2006;104: 1070-80.

10. Lenhardt R, Marker E, Goll V, Tschernich H, Kurz A, Sessler DI, Narzt E, Lackner F. Mild intraoperative hypothermia prolongs postanesthetic recovery. Anesthesiology. 1997;87:1318-23.

11. Sessler DI. A proposal for new temperature monitoring and thermal management guidelines. Anesthesiology. 1998;89: 1298-300.

12. Sessler DI. Perioperative heat balance. Anesthesiology. 2000;92: 578-96.

13. Matsukawa T, Sessler DI, Sessler AM, Schroeder M, Ozaki M, Kurz A, Cheng C. Heat flow and distribution during induction of general anesthesia. Anesthesiology. 1995;82:662-73.

14. Matsukawa T, Sessler DI, Christensen R, Ozaki M, Schroeder M. Heat flow and distribution during epidural anesthesia. Anesthesiology. 1995;83:961-7.

15. Joris H, Ozaki M, Sessler DI, Hardy AF, Lamay M, McGuire J, Blanchard D, Schroeder M, Moayeri A. Epidural anesthesia impairs both central and peripheral thermoregulatory control during general anesthesia. Anesthesiology. 1994;80:268-77.

16. Roe CF. Effect of bowel exposure on body temperature during surgical operations. Am J Surg. 1971;122:13-5.

17. Kurz A, Kurz M, Poeschl G, Faryniak B, Redl G, Hackl W. Forced-air warming maintains intraoperative normothermia better than circulating-water mattresses. Anesth Analg. 1993;77:89-95.

18. Negishi C, Hasegawa K, Mukai S, Nakagawa F, Ozaki M, Sessler DI. Resistive-heating and forced-air warming are comparably effective. Anesth Analg. 2003;96:1683-7.

19. Leslie K, Sessler DI. Perioperative hypothermia in the high-risk surgical patient. Best Pract Res Clin Anaesthesiol. 2003;17: 485-98.

20. Insler SR, Bakri MH, Nageeb F, Mascha E, Mihaljevic T, Sessler DI. An evaluation of a full-access underbody forced-air warming system during near-normothermic, on-pump cardiac surgery. Anesth Analg. 2008;106:746-50.

21. Taguchi A, Ratnaraj J, Kabon B, Sharma N, Lenhardt R, Sessler DI, Kurz A. Effects of a circulating-water garment and forced-air warming on body heat content and core temperature. Anesthesiology. 2004;100:1058-64.

22. Hynson J, Sessler DI. Intraoperative warming therapies: a comparison of three devices. J Clin Anesth. 1992;4:194-9.

23. Lund CC, Browder NC. The estimation of areas of burns. Surg Gynecol Obstet. 1944;79:352-8.

24. Ramanathan NL. A new weighting system for mean surface temperature of the human body. J Appl Physiol. 1964;19:531-3.

25. Burton AC. Human calorimetry. II. The average temperature of the tissues of the body. J Nutr. 1935;9:261-80.

26. Lenhardt R, Sessler DI. Estimation of mean body temperature from mean skin and core temperature. Anesthesiology. 2006;105: $1117-21$.

27. Janicki PK, Higgins MS, Janssen J, Johnson RF, Beattie C. Comparison of two different temperature maintenance strategies during open abdominal surgery: upper body forced-air warming versus whole body water garment. Anesthesiology. 2001;95: 868-74.

28. Janicki PK, Stoica C, Chapman WC, Wright JK, Walker G, Pai R, Walia A, Pretorius M, Pinson CW. Water warming garment versus forced air warming system in prevention of intraoperative 
hypothermia during liver transplantation: a randomized controlled trial. BMC Anesthesiol. 2002;2:7.

29. Wadhwa A, Komatsu R, Orhan-Sungur M, Barnes P, In J, Sessler DI, Lenhardt R. New circulating-water devices warm more quickly than forced-air in volunteers. Anesth Analg. 2007; 105:1681-7.

30. Burke WEA, Mekjavic IB. Estimation of regional cutaneous cold sensitivity by analysis of the gasping response. J Appl Physiol. 1991;71:1933-40.

31. Hardy JD, Oppel TW. The thermal response of the skin to radiation. Physics. 1936;7:466-79.
32. Gendron F. "Burns" occurring during lengthy surgical procedures. J Clin Eng. 1980;5:19-26.

33. Cheney FW, Posner KL, Caplan RA, Gild WM. Burns from warming devices in anesthesia. A closed claims analysis. Anesthesiology. 1994;80:806-10.

34. Gali B, Findlay JY, Plevak DJ. Skin injury with the use of a water warming device. Anesthesiology. 2003;98:1509-10.

35. Giesbrecht GG, Ducharme MB, McGuire JP. Comparison of forced-air patient warming systems for perioperative use. Anesthesiology. 1994;80:671-9. 